\title{
Seismic Performance of Chinese Traditional Timber Frames
}

\author{
Deshan Yang, ${ }^{\mathrm{a}, \mathrm{b}, *}$ Ming $\mathrm{Xu},{ }^{\mathrm{a}, \mathrm{b}}$ and Zhongfan Chen ${ }^{\mathrm{a}, \mathrm{b}}$ \\ Chinese traditional timber frames are known for their mortise-tenon joints \\ and wooden planks shear walls. To investigate the seismic behavior of the \\ structural system, three full-scale timber frames were subjected to in-plane \\ quasi-static loading. The hysteresis characteristics, lateral load-carrying \\ capacities, lateral stiffnesses, and energy dissipation capacities of the \\ timber frames were investigated. The results showed that the hysteretic \\ loops of all specimens exhibited pinching, and the column and beam \\ components were nearly intact after the test. The traditional wooden \\ frames had large deformability. The installation of the infilled timber shear \\ wall brought great improvements in lateral resistance and energy \\ dissipation to the bare frames. The initial stiffness of the timber frame \\ infilled with timber shear wall was $0.113 \mathrm{kN} / \mathrm{mm}$, which was $56.9 \%$ and \\ $11.9 \%$ greater than those of the bare frame specimen F1 and specimen \\ F2, respectively. The results from the experimental analyses can serve as \\ a technical basis for the development of seismic design methods and \\ strengthening designs of such structures in practical engineering.
}

Keywords: Traditional timber frame; Mortise-tenon joint; Timber shear wall; Quasi-static cyclic test; Hysteretic performance; Energy dissipation

Contact information: a: Key Laboratory of Concrete and Pre-stressed Concrete Structures of the Ministry of Education, Southeast University, 02, Southeast University Road, Nanjing, 211189, P.R. China; b: School of Civil Engineering, Southeast University, 02, Southeast University Road, Nanjing, 211189, P.R. China;

* Corresponding author:15251836139@163.com

\section{INTRODUCTION}

Traditional wood structures skillfully combine the wood components through mortise-tenon joints, which effectively limit rotation of the wood components and ensure the reliability of the wood structure. This combination also provides the wood structure with better deformation capacity, so the mortise-tenon joints are also key to the anti-seismic properties of the traditional wood structures. In the event of a strong earthquake, although the mortise-tenon joint will be loose, it will not fall apart. This kind of joint can effectively absorb the energy transmitted to the structure by the earthquake, greatly reduce the seismic response of the structure, and ensure the safety of the structure.

Under the action of a horizontal load, the timber frame exhibits rocking characteristics. The energy input into the timber structure is divisible into three parts: the hysteretic energy, the gravitational potential energy transformed by the uplift of the structure, and the elastic strain energy transformed by the elastic deformation of the components. The hysteretic energy dissipation is the energy consumed by friction and plastic deformation of the structural components. The gravitational potential energy and elastic strain energy are stored in the timber structure (Meng et al. 2018; Meng 2019).

Yang et al. (2021). "Seismic response, timber frames," BioResources 16(3), 6135-6146. 6135 
In the health monitoring of existing ancient wooden structures with mortise-tenon connections and column foot floating as the main structural characteristics, overall deformation control of the structure should be taken as the key point, and it has been proposed that the ancient wooden structures have strong self-recovery characteristics. The hysteretic curve is thin, long, and S-shaped, with obvious pinching. Due to the mortisetenon connections and column foot floating, the ancient wooden structures have good ductility, which ensures that the ancient wooden structures can produce large lateral displacement when resisting the action of horizontal external forces, reducing the damage of components and connection parts (Chen 2017; Chen et al. 2018).

Through low-cycle reciprocating load tests of a full-scale single-span model, forcedisplacement hysteretic curves, skeleton curves, the stiffness degradation law, and energy dissipation capacity have been analyzed to evaluate the hysteretic performance of the wood structure. The deformation of the timber frame is mainly expressed as rotation of the columns, friction and slip between components, and plastic deformation. The rotational deformation of the timber frame is mainly manifested as the rocking of the columns, which causes the lifting and resetting of the whole structure. Friction slip between the components in lateral displacement is also obvious, while the plastic deformation is small. In the monitoring of ancient wooden buildings, in addition to the deformation control of the whole structure, it is necessary to focus on the deformation of the columns. Increased vertical load improves the ultimate bearing capacity and ultimate deformation capacity of the timber frame and delays the failure of the structure (Shi 2018; Shi et al. 2020).

The lateral resistance of the timber frame increases with increasing joint rigidity. If the joints are simplified as rigid joints, the bearing capacity of the timber frame will be overestimated. If the joints are simplified as hinge joints, the bearing capacity of the timber frame will be underestimated. When the lateral deformation of the frame is small, the total bending moment of the frame mainly comes from the bending moment of the column foot. When the lateral deformation of the frame is large, the total bending moment of the frame mainly comes from the bending moments of the mortise-tenon joints. A simplified finite element model of a frame connected by column feet and mortise-tenon joints has been established. The effectiveness of the simplified model was verified by a solid element model, and a universal modeling method of ancient building wood structures was obtained. The rotational performance of traditional wood structure column feet has been analyzed. Compressive reaction forces and friction forces occur at the interface between the column foot and the stone foundation, and a restoring moment occurs to the column foot. A theoretical model of the restoring moment at the column foot considering compression effects under different states has been proposed, which could be used as the basis of mechanical analysis to predict the performance of traditional wood structures ( $\mathrm{He}$ and Wang 2018; He 2019).

Dynamic testing and analysis of ancient timber structures with different damage degrees of column feet in the orthogonal direction have been performed. Damage of the column foot reduces the natural frequency of the structure. Under the same seismic wave, the column foot reaction force of the damaged model is smaller than that of the lossless model, while the acceleration and displacement responses of the damaged model are larger than those of the lossless model. Increasing the vertical load on the top of the column increases the ultimate restoring moment of the column foot joint, but the initial rotational stiffness changes little (Qin et al. 2018; Qin 2018).

Chen et al. (2020) studied the influence of joint failure on the seismic performance of ancient timber structures. By changing the size of the mortise and controlling the width

Yang et al. (2021). "Seismic response, timber frames," BioResources 16(3), 6135-6146. 6136 
of the mortise compression zone and the clearance between the mortise and the tenon, the deterioration of the mortise-tenon joint was simulated. As the gap increased, the sliding between the tenon and mortise became increasingly obvious. Ren et al. (2021) studied cross-shaped joints with dowels in Chinese traditional wood structures. The cross-shaped joints with dowels had higher bearing capacities than those without dowels. In addition, the dowel acted as an effective component to greatly improve the rotational ductility of the joints and limit tenon pullout.

It is necessary to study the overall spatial mechanical performance and dynamic characteristics of the structure. Xue et al. (2019) produced a two-layer and two-span column-and-tie timber frame model with scale ratio of 1:2. The main body of the model was divided vertically into three parts: the first layer of the column frame layer, the second layer of the column frame layer, and the roof layer. A shaking table test was performed. As the seismic intensity increased, the plastic deformation of the structure increased, and the energy dissipation of each layer increased gradually. The results showed that the model had good energy dissipation capacity, and the energy dissipation of the first-floor column frame was the largest, while the energy dissipation of the column foot was the smallest (Xue et al. 2019).

Zhang et al. (2020) studied the applicability of a fast nonlinear analytical model in predicting the overall response of Chinese timber traditional buildings under earthquake. Ma et al. (2020) studied the embedded compression mechanisms of joints under cyclic loading and derived a simplified equation to predict the moment-rotation relationship. Zhao et al. (2019) performed shaking table tests on an ancient wood structure strengthened with carbon-fiber-reinforced polymer. The peak displacement of each layer presented an inverse triangular distribution, which indicated that the structural deformation was mainly shear deformation.

To determine the reasons for the good performance of Chinese traditional timber structures under earthquake, Xie et al. (2019) studied the energy dissipation mechanisms of Chinese traditional timber structures through shaking table tests. A new damage assessment model based on energy dissipation was proposed. Due to the friction and embedment between components of the wood structures, the damping ratios of traditional wood structures were generally higher than those of reinforced concrete structures and steel structures.

In order to study seismic performance and strengthening methods of wood frame with masonry infill walls, three small-scale wall specimens were tested under low reversed cyclic loadings. The main failure characteristics of wood frames with masonry infilled walls are shear cracks of infilled walls, and there is no obvious damage to the wood frames. In the case of without reinforcement, the infilled walls are prone to collapse out of plane, which can be effectively improved by external steel plates and embedded steel bars reinforcement (Jing et al. 2016).

In this study, the structural system utilizes wooden planks as infills, instead of masonry walls, to provide lateral resistance. To investigate the seismic behavior of such a structural system, three full-scale specimens of single story-one bay traditional timber frames with mortise tenon joints were subjected to in-plane quasi-static loading. This study examined the seismic performance of traditional timber frames. The strength, stiffness, energy dissipation capacity, and failure mechanisms of single-story single-bay timber frames were investigated. 


\section{EXPERIMENTAL}

\section{Specimen Design}

Three full-scale single-story single-bay traditional timber frames were fabricated and tested. Each of the specimens had a span of $2600 \mathrm{~mm}$ and a height of $3200 \mathrm{~mm}$. Specimen F1 and specimen F2 consisted of the beams and round columns. The diameter of the round columns was $200 \mathrm{~mm}$. The beams and columns of the frames were connected by mortise-tenon joints. For specimen F3, the timber shear wall was infilled. The wooden shear walls comprised several wooden planks. The planks were inserted into the grooves of the exterior timber frame. The geometric parameters of specimen F1 is listed in Table 1. The geometric parameters of specimen F2 and specimen F3 are listed in Table 2. The layouts of the specimens and the main dimensions are illustrated in Fig. 1.

Small clear specimens were fabricated and tested to determine the material properties. The material properties of the small clear specimens were tested in terms of Chinese standards GB/T 1935-2009 (2009), GB/T 15777-1995 (1995), and GB/T 19382009 (2009). The compressive strength and modulus of elasticity parallel to the wood grain were $32.0 \mathrm{MPa}$ and $10040 \mathrm{MPa}$, respectively, and the tensile strength parallel to the grain was $72.2 \mathrm{MPa}$.

Table 1. Dimensions of the Specimen F1

\begin{tabular}{|l|c|c|}
\hline \multicolumn{2}{|c|}{ Member } & Component Dimensions (mm) \\
\hline \multirow{3}{*}{ Column } & Diameter & 200 \\
\cline { 2 - 3 } & Height & 3200 \\
\hline \multirow{3}{*}{ Beam } & Length & 2400 \\
\cline { 2 - 3 } & Width & 120 \\
\cline { 2 - 3 } & Height & 200 \\
\hline \multirow{3}{*}{ Tenon } & Length & 400 \\
\cline { 2 - 3 } & Width & 60 \\
\cline { 2 - 3 } & Height & 200 \\
\hline
\end{tabular}

Table 2. Dimensions of the Specimen F2 and Specimen F3

\begin{tabular}{|l|l|c|}
\hline \multicolumn{2}{|l|}{ Member } & Dimensions $/ \mathrm{mm}$ \\
\hline \multirow{4}{*}{ Column } & Diameter & 200 \\
\cline { 2 - 3 } & Height & 3200 \\
\hline \multirow{4}{*}{ Beam } & Length & 2400 \\
\cline { 2 - 3 } & Width & 120 \\
\cline { 2 - 3 } & Height & 200 \\
\hline \multirow{5}{*}{ Tenon at Bop Beam } & Height of the Big Tenon Head & 200 \\
\cline { 2 - 3 } & Height of the Small Tenon Head & 100 \\
\cline { 2 - 3 } & Tenon Width & 60 \\
\cline { 2 - 3 } & Length of the Big Tenon Head & 100 \\
\cline { 2 - 3 } & Length of the Small Tenon Head & 300 \\
\hline & Length & 400 \\
\cline { 2 - 3 } & Width & 60 \\
\cline { 2 - 3 } & Height & 200 \\
\hline
\end{tabular}

Yang et al. (2021). "Seismic response, timber frames," BioResources 16(3), 6135-6146. 6138 


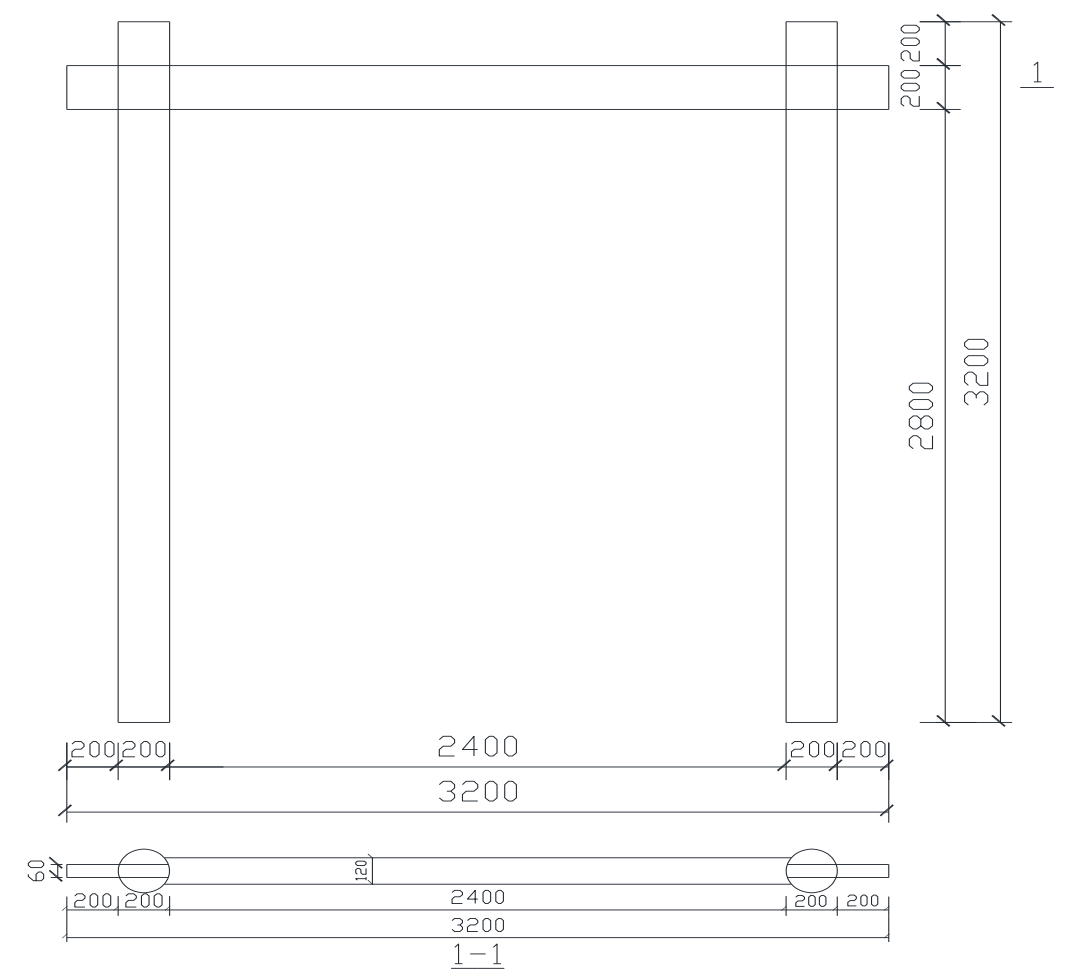

(a)

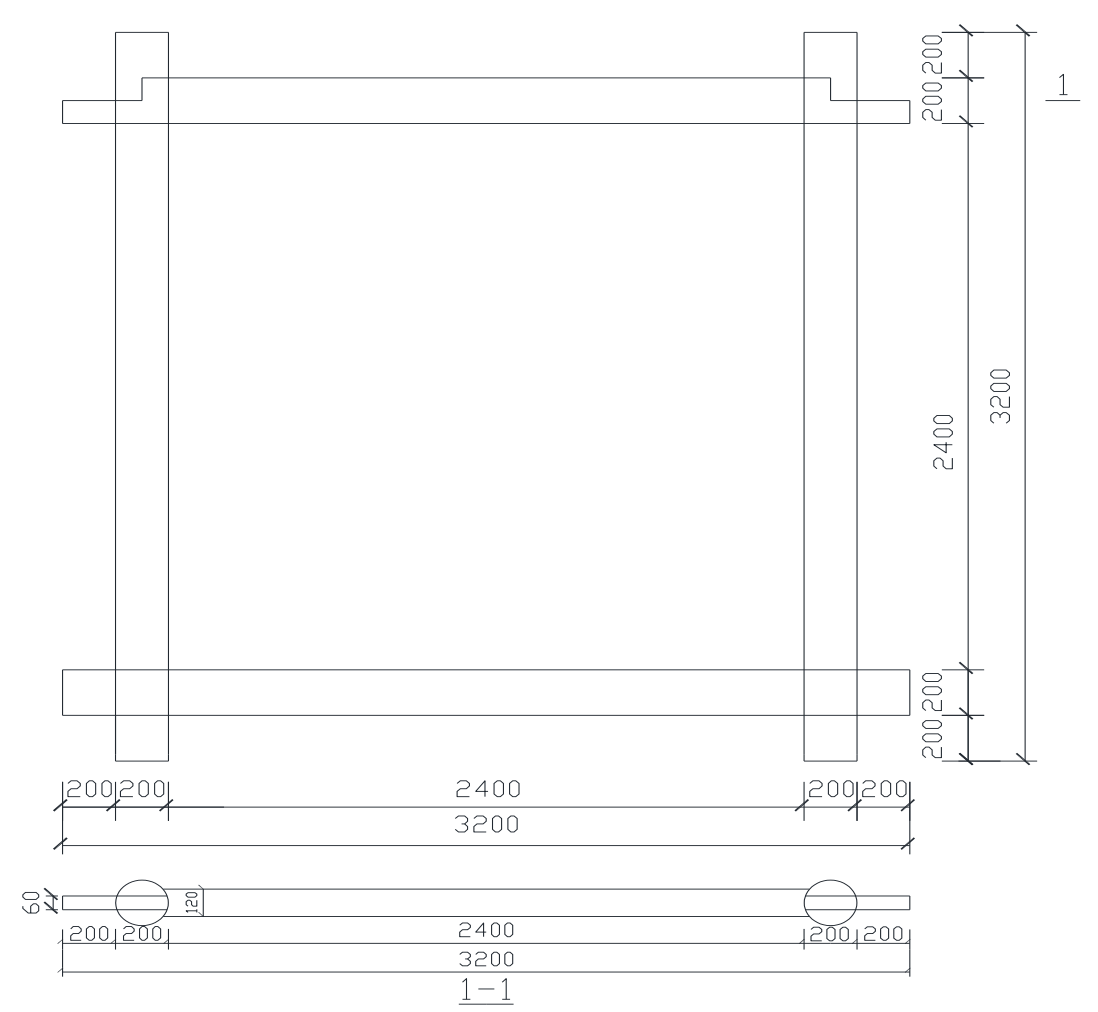

(b)

Yang et al. (2021). "Seismic response, timber frames," BioResources 16(3), 6135-6146. 6139 


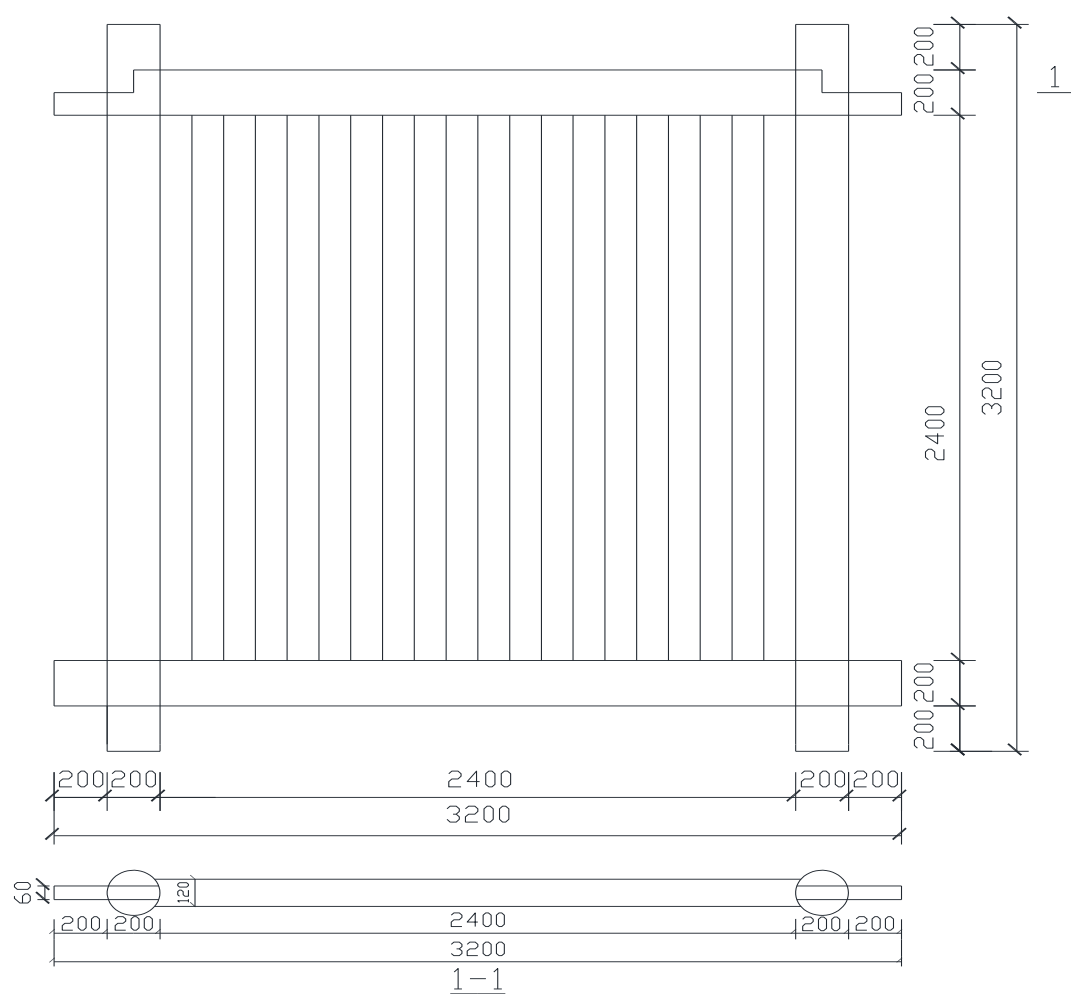

(c)

Fig. 1. Configurations of specimens (a) F1, (b) F2, and (c) F3. All dimensions are in mm.

\section{Test Setup}

Specimens were tested under reversed cyclic lateral loading, simulating seismic action. For actual structures, columns are directly erected on cornerstones. In this study, the wooden frame was supported by the two steel rotating supports to simulate the boundary condition.

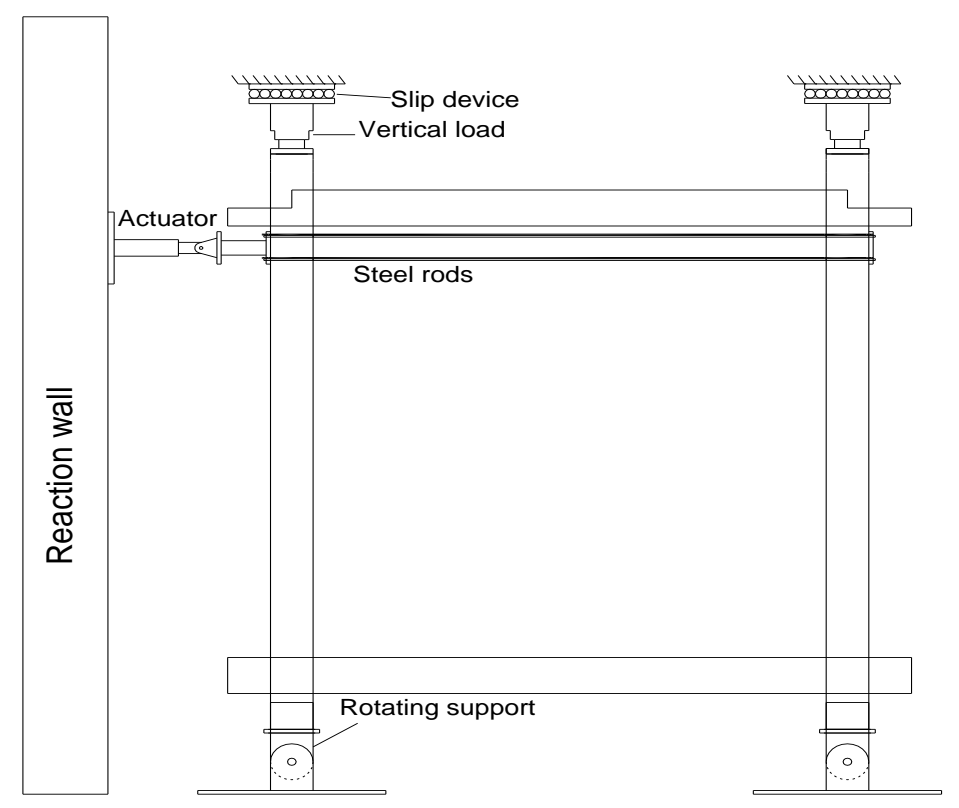

Fig. 2. Test setup for cyclic loading 
The hinge supports were fixed with the strong floor of the laboratory using anchor bolts. The horizontal load was applied via a hydraulic servo-actuator. The two columns were connected together through four steel bars, which were evenly distributed on both sides of the specimen and fastened through two steel plates. Out-of-plane displacement of the frame was prevented by a system of lateral supports placed on both sides of the frame. A schematic drawing of the test setup is shown in Fig. 2, and a picture of the experimental apparatus is shown in Fig. 3.

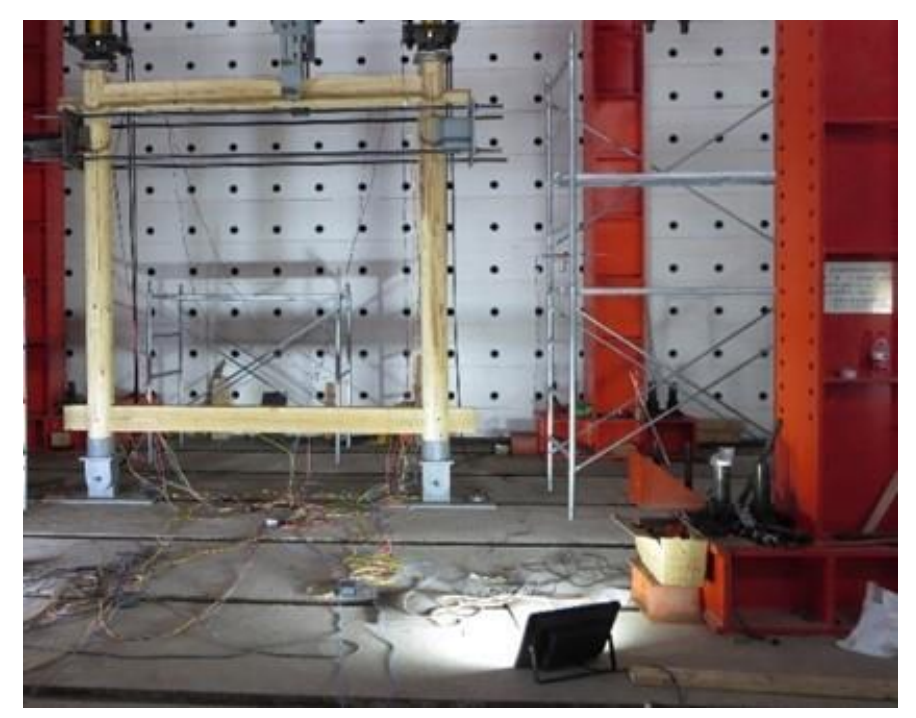

Fig. 3. Picture of experimental apparatus

\section{Test Procedures}

Quasi-static reversed cyclic tests were implemented. The cyclic loading protocol is shown in Fig. 4. The loading protocol began with an amplitude of $10 \mathrm{~mm}$. The reverse cyclic displacement was applied with a $10-\mathrm{mm}$ increment. Each displacement cycle was repeated three times.

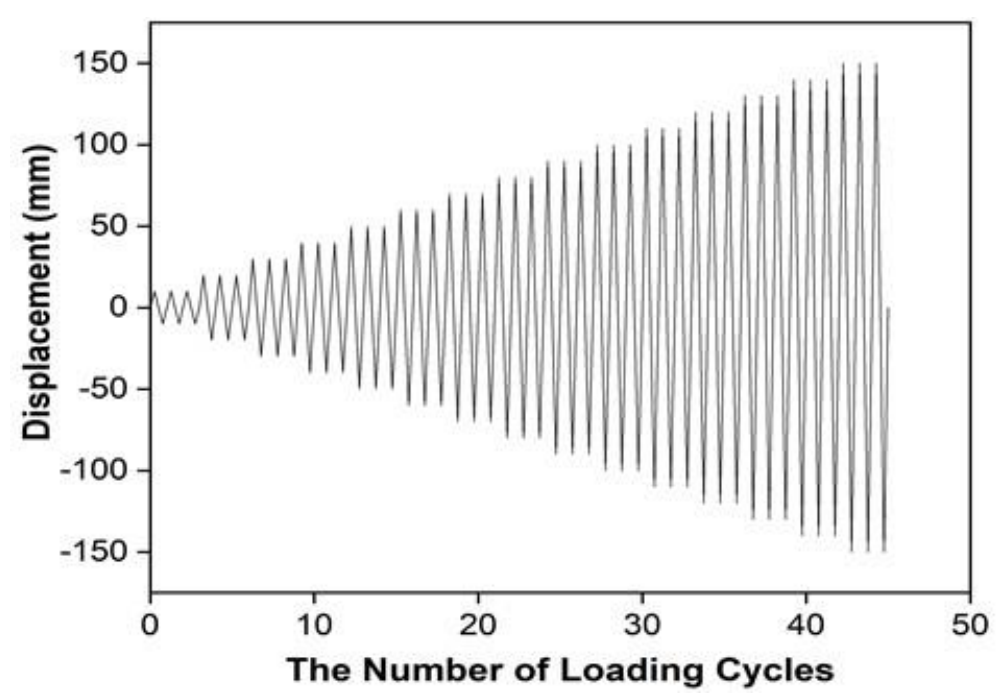

Fig. 4. Low-cyclic reversed loading procedure 


\section{RESULTS AND DISCUSSION}

Quasi-static cyclic testing is an important way to simulate earthquake load, and it provides important information about the overall mechanical properties of frames subjected to seismic actions.

\section{Hysteretic Performance}

Hysteresis curves reflect the overall seismic performance of the structures. The force-displacement hysteretic curves that were observed during testing are illustrated in Fig. 5. The hysteresis curves exhibited pinching behavior, and the areas of the hysteresis loops increased with increasing displacement (Fig. 5), apparently indicating the slipping characteristics between mortises and tenons.

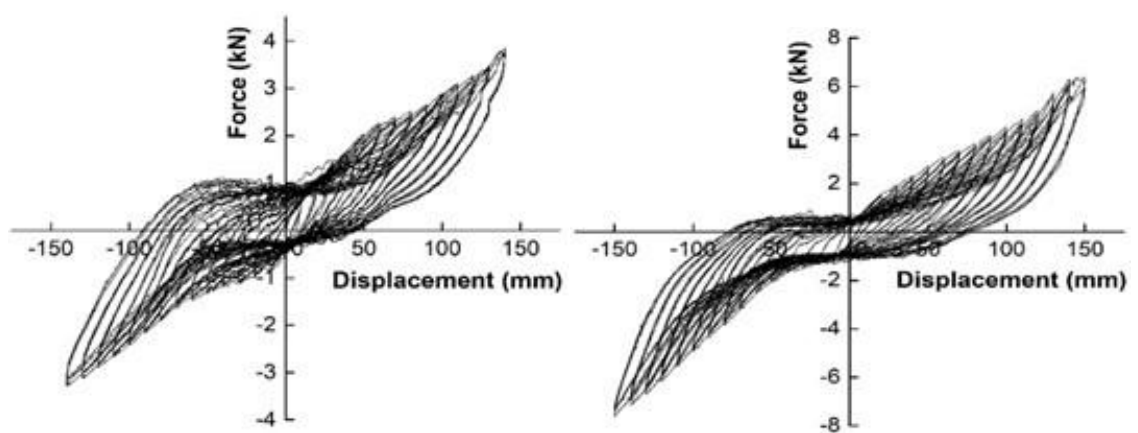

(a)

(b)

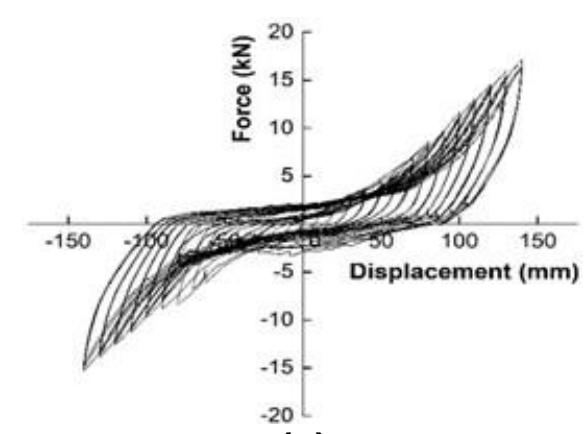

(c)

Fig. 5. Force-displacement hysteretic curves: (a) F1, (b) F2, and (c) F3

\section{Lateral Load Capacity}

As shown in Fig. 6, the addition of the timber shear wall significantly increased the strength. The timber shear wall was effective in resisting lateral loads under cyclic loads. Due to the strengthening of the frame by the timber shear wall, the bearing capacity of F3 greatly exceeded those of specimens F1 and F2. 


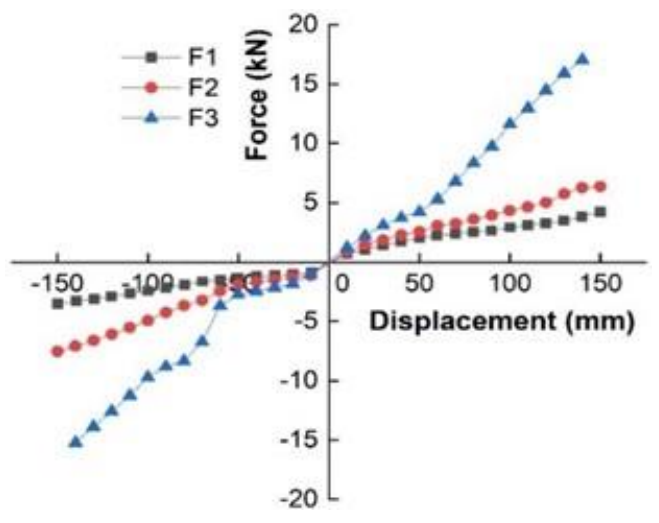

Fig. 6. Skeleton curves

\section{Lateral Stiffness}

Lateral stiffness is an important index for evaluating the performance of laterally resistant components. The lateral stiffness under reversed cyclic loading was determined using the secant stiffness. The secant stiffness calculation was based on Eq. 1,

$$
K_{\mathrm{i}}=\frac{\left|+P_{\mathrm{i}}\right|+\left|-P_{\mathrm{i}}\right|}{\left|+\Delta_{\mathrm{i}}\right|+\left|-\Delta_{\mathrm{i}}\right|}
$$

in which $K_{\mathrm{i}}$ is the secant stiffness of cycle $\mathrm{i}(\mathrm{kN} / \mathrm{mm}),+P_{\mathrm{i}}$ denotes the maximum positive load of cycle $\mathrm{i}(\mathrm{kN}),+\Delta_{\mathrm{i}}$ indicates the displacement corresponding to the maximum positive load of cycle $\mathrm{i}(\mathrm{mm}),-P_{\mathrm{i}}$ denotes the minimum negative load of cycle $\mathrm{i}(\mathrm{kN})$, and $-\Delta_{\mathrm{i}}$ indicates the displacement corresponding to the minimum negative load of cycle $\mathrm{i}(\mathrm{mm})$.

Table 3. Secant Stiffness Values of Wood Frames $(\mathrm{kN} / \mathrm{mm})$

\begin{tabular}{|c|c|c|c|c|c|c|}
\hline Specimen Number & $\begin{array}{c}\Delta=10 \\
\mathrm{~mm}\end{array}$ & $\begin{array}{c}\Delta=20 \\
\mathrm{~mm}\end{array}$ & $\begin{array}{c}\Delta=30 \\
\mathrm{~mm}\end{array}$ & $\begin{array}{c}\Delta=40 \\
\mathrm{~mm}\end{array}$ & $\begin{array}{c}\Delta=50 \\
\mathrm{~mm}\end{array}$ & $\begin{array}{c}\Delta=60 \\
\mathrm{~mm}\end{array}$ \\
\hline $\mathrm{F} 1$ & 0.072 & 0.050 & 0.042 & 0.036 & 0.032 & 0.030 \\
\hline $\mathrm{F} 2$ & 0.101 & 0.069 & 0.056 & 0.049 & 0.044 & 0.046 \\
\hline $\mathrm{F} 3$ & 0.113 & 0.101 & 0.087 & 0.077 & 0.067 & 0.075 \\
\hline
\end{tabular}

The secant stiffness values of the three timber frames are shown in Table 3 . The secant stiffness value of specimen F3 was higher than those of the other frames. The initial secant stiffness of specimen F3 was $0.113 \mathrm{kN} / \mathrm{mm}$. For the frames without timber shear walls (specimen F1 and specimen F2), the initial secant stiffnesses were $0.072 \mathrm{kN} / \mathrm{mm}$ and $0.101 \mathrm{kN} / \mathrm{mm}$, respectively. The initial secant stiffness of specimen F3 was $56.94 \%$ greater than that of specimen F1 and $11.88 \%$ greater than that of specimen F2.

\section{Energy Dissipation Characteristics}

Energy dissipation is an important indicator of structural seismic performance. The energy dissipation capacity refers to the amount of energy absorbed by a structure or component under cyclic earthquake load. Under cyclic loading, the energy dissipation $E_{\text {loop }}$ is equal to the area enclosed by the force-displacement hysteretic loop A-B-C-D, as shown in Fig. 7. A large hysteretic loop represents a better energy dissipation capacity of the structure. 


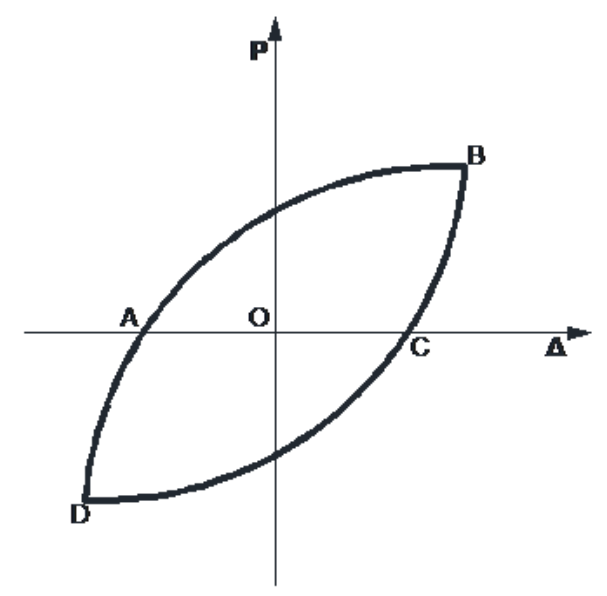

Fig. 7. Lateral force-displacement hysteretic loop

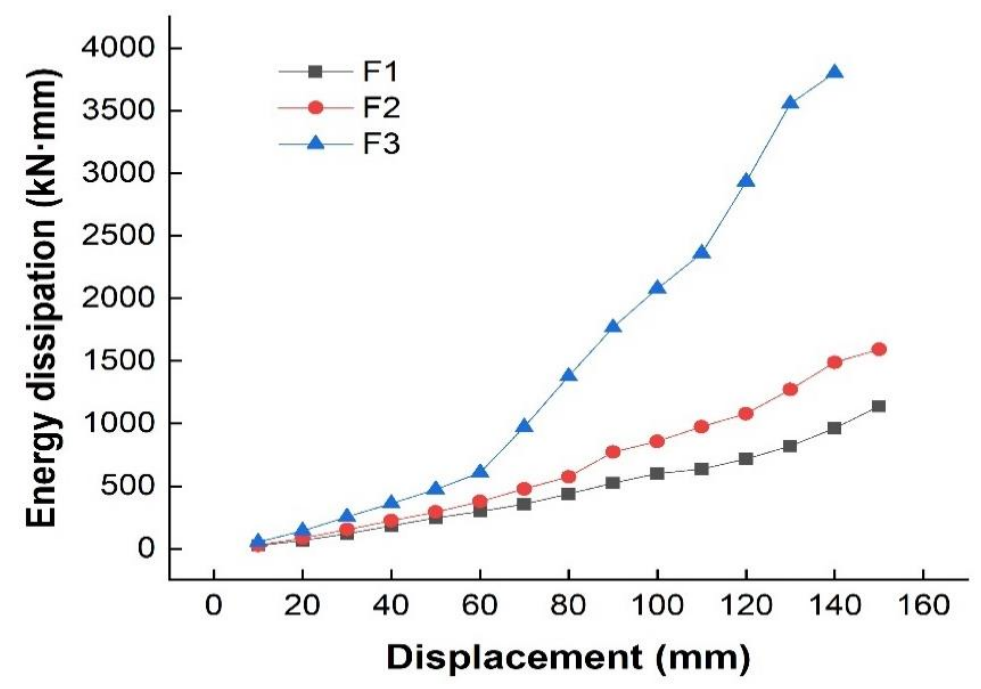

Fig. 8. Energy dissipation analysis of the specimens

The energy dissipations of the three timber frames for each loading amplitude are shown in Fig. 8. As the lateral displacement increased, the energy dissipated by the three timber frames increased. The amount of energy dissipated by specimen F3 was the greatest among all the specimens. The energy dissipation of F3 was approximately $3800 \mathrm{kN} \cdot \mathrm{mm}$ at a displacement of $140 \mathrm{~mm}$, while the energy dissipations were $1140 \mathrm{kN} \cdot \mathrm{mm}$ and 1590 $\mathrm{kN} \cdot \mathrm{mm}$ at a displacement of $150 \mathrm{~mm}$ in $\mathrm{F} 1$ and $\mathrm{F} 2$, respectively.

\section{CONCLUSIONS}

This paper presented the results of cyclic loading tests of three full-scale, one-story, one-bay traditional mortise-tenon jointed timber frames, based on traditional Chinese architecture. The lateral load capacities, hysteric curves, skeleton curves, lateral stiffness and energy dissipation capacity of the three frames were analyzed. The following conclusions are drawn based on the test and comparison results. 
1. In terms of improving the bearing capacity, the infill wood shear walls were very effective. There were obvious pinch phenomena in the hysteresis curves, and the areas of the hysteresis loops increased with increasing displacement. All the frames exhibited quite high deformability under lateral loads without any significant damage.

2. The installation of the timber shear wall resulted in an increase in the lateral stiffness of the bare frame. The initial secant stiffnesses of bare frames (F1 and F2) were improved 1.57 and 1.12 times, respectively.

3. The amount of energy dissipated by specimen F3 was the greatest among all the specimens. The timber shear wall provided high energy dissipation capacity. It is thus advised that adding timber shear walls in the frames can improve the seismic performance of the structure.

4. The timber frame infilled with wood shear wall was an excellent lateral force resisting system in traditional timber structure buildings. The research results can provide technical support for the application of this kind of wood shear wall system in practical engineering.

\section{ACKNOWLEDGMENTS}

This research was supported by the National Key R\&D Program of China (No. 2018YFD1100402).

\section{REFERENCES CITED}

Chen, J. Y. (2017). Hysteretic Behavior of Full Scale Timber Structure Specimen with Dou-Gong Sets and Four Columns in Song Dynasty by Pseudo-Static Tests and Simulation Analysis, Ph.D. Dissertation, Taiyuan Univ. of Technol., Taiyuan, China.

Chen, J., Li, T., Yang, Q., Shi, X., and Zhao, Y. (2018). "Degradation laws of hysteretic behaviour for historical timber buildings based on pseudo-static tests," Engineering Structures 156, 480-489. DOI: 10.1016/j.engstruct.2017.11.054

Chen, L.-K., Li, S.-C., Zhao, K.-P., Chen, Z.-Y., Song, T., Zhang, L., and Jang, Z.-J. (2020). "Experimental and numerical investigation on seismic performance of oneway straight mortise-tenon joints based on a novel method to simulate damage of deteriorated ancient Chinese timber buildings," Journal of Performance of Constructed Facilities 34(2). DOI: 10.1061/(ASCE)CF.1943-5509.0001390

GB/T 15777-1995 (1995). "Method for determination of the modulus of elasticity in compressive parallel to grain of wood," Standardization Admin. of China, Beijing.

GB/T 1935-2009 (2009). "Method of testing in compressive strength parallel to grain of wood," Standardization Administration of China, Beijing, China.

GB/T 1938-2009 (2009). "Method of testing in tensile strength parallel to grain of wood," Standardization Administration of China, Beijing, China.

He, J., and Wang, J. (2018). "Theoretical model and finite element analysis for restoring moment at column foot during rocking," Journal of Wood Science 64(2), 97-111. DOI: $10.1007 / \mathrm{s} 10086-017-1677-5$

He, J. X. (2019). Study on Mechanical Properties of Key Joints and Column Frame in

Yang et al. (2021). "Seismic response, timber frames," BioResources 16(3), 6135-6146. 6145 
Traditional Timber Structure, Ph.D. Dissertation, Beijing Jiaotong Univ., Beijing. Jing, D., Yan, J., and Cao, S. (2016). "Experimental study on seismic performance of brick masonry infill walls with wood frame strengthened by embedded steel bars and external steel plates," Journal of Hunan University (Natural Science) 43(7), 43-49. DOI: 10.16339/j.cnki.hdxbzkb.2016.07.006

Ma, L., Xue, J., Dai, W., Zhang, X., and Zhao, X. (2020). "Moment-rotation relationship of mortise-through-tenon connections in historic timber structures," Construction and Building Materials 232. DOI: 10.1016/j.conbuildmat.2019.117285

Meng, X. J. (2019). Study on the Seismic Performance and Seismic Mechanism of Traditional Timber Structure in Song Dynasty, Ph.D. Dissertation, Taiyuan University of Technology, Taiyuan, China.

Meng, X., Li, T., Yang, Q., and Wei, J. (2018). "Seismic mechanism analysis of a traditional Chinese timber structure based on quasi-static tests," Structural Control and Health Monitoring 25(10). DOI: 10.1002/stc.2245

Qin, S. J. (2018). Structural Performance and Evaluation Method of the Connecting Joints in Heritage Timber Buildings under Damage State, Ph.D. Dissertation, Beijing Jiaotong University, Beijing, China.

Qin, S., Yang, N., and Dai, L. (2018). "Rotational behavior of column footing joint and its effect on the dynamic characteristics of traditional Chinese timber structure," Shock and Vibration. DOI: 10.1155/2018/9726852

Ren, G., Xue, J., Xu, D., and Ma, L. (2021). "Experimental and theoretical analysis on rotation performance of cross-shaped joints with dowel in traditional timber structures," Journal of Building Engineering 37, 102163. DOI: 10.1016/j.jobe.2021.102163

Shi, X., Li, T., Chen, Y. F., Chen, J., and Yang, Q. (2020). "Full-scale tests on the horizontal hysteretic behavior of a single-span timber frame," International Journal of Architectural Heritage 14(3), 398-414. DOI: 10.1080/15583058.2018.1547799

Shi, X. W. (2018). Experimental Study and Theoretical Analysis for Hysteretic Behaviors of Full-scale and Single-span Traditional Timber Structure, Ph.D. Dissertation, Taiyuan University of Technology, Taiyuan, China.

Xie, Q., Wang, L., Zhang, L., Hu, W., and Zhou T. (2019). "Seismic behaviour of a traditional timber structure: Shaking table tests, energy dissipation mechanism and damage assessment model," Bulletin of Earthquake Engineering 17(3), 1689-1714. DOI: $10.1007 / \mathrm{s} 10518-018-0496-4$

Xue, J., Xu, D., Ren, G., and Guo, R. (2019). "Shake table test on seismic performance of column and tie wooden structure in traditional residence," China Civil Engineering Journal 52(12), 1-10. DOI: 10.15951/j.tmgcxb.2019.12.001

Zhang, X., Wu, C., Xue, J., and Ma, H. (2020). "Fast nonlinear analysis of traditional Chinese timber-frame building with Dou-Gon," International Journal of Architectural Heritage 14(8), 1252-1268. DOI: 10.1080/15583058.2019.1604847

Zhao, X.-b., Zhang, F.-1., Xue, J.-y., and Ma, L.-L. (2019). "Shaking table tests on seismic behavior of ancient timber structure reinforced with CFRP sheet," Engineering Structures 197. DOI: 10.1016/j.engstruct.2019.109405

Article submitted: May 10, 2021; Peer review completed: July 17, 2021; Revised version received: July 18, 2021; Accepted: July 19, 2021; Published: July 21, 2021.

DOI: 10.15376/biores.16.3.6135-6146

Yang et al. (2021). "Seismic response, timber frames," BioResources 16(3), 6135-6146. 6146 